\title{
International Handbook on Regulating Nanotechnologies
}

Edited by

Graeme A. Hodge

Director, Monash Centre for Regulatory Studies, Faculty of Law, Monash University, Australia

Diana M. Bowman

Senior Research Fellow, Melbourne School of Population Health, the University of Melbourne, Australia

Andrew D. Maynard

Director, Risk Science Center, University of Michigan, USA

\section{Edward Elgar}

Cheltenham, UK • Northampton, MA, USA 
(C) Graeme A. Hodge, Diana M. Bowman and Andrew D. Maynard 2010

All rights reserved. No part of this publication may be reproduced, stored in a retrieval system or transmitted in any form or by any means, electronic, mechanical or photocopying, recording, or otherwise without the prior permission of the publisher.

Published by

Edward Elgar Publishing Limited

The Lypiatts

15 Lansdown Road

Cheltenham

Glos GL50 2JA

UK

Edward Elgar Publishing, Inc.

William Pratt House

9 Dewey Court

Northampton

Massachusetts 01060

USA

A catalogue record for this book

is available from the British Library

Library of Congress Control Number: 2010925965

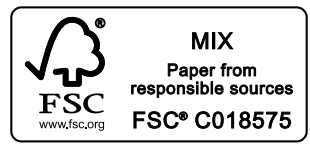

ISBN 9781848446731 (cased)

Typeset by Servis Filmsetting Ltd, Stockport, Cheshire

Printed and bound by MPG Books Group, UK 


\section{International coordination and cooperation: the next agenda in nanomaterials regulation \\ Robert Falkner, Linda K. Breggin, Nico Jaspers, John Pendergrass and Read Porter}

Nanotechnologies are set to transform industrial society. They promise benefits in a wide range of applications, from health care to food, cosmetics, chemicals, information technology and energy storage. The manipulation of matter or creation of structures down to the molecular level (typically at a scale of approximately 100 nanometres or less, a nanometre being one-billionth of a metre) has led to the creation of novel materials, so-called engineered nanomaterials, which are already being used in numerous consumer products. Additional commercial applications can be expected in coming years.

Our understanding of how nanomaterials interact with the environment and the human body has not kept pace with the development of nanotechnologies. Early results of research suggest that the safety of all nanomaterials cannot be taken for granted (see, for example, the recent reviews by the Royal Society and the Royal Academy of Engineering (RS-RAE) (2004) and the Royal Commission on Environmental Pollution (RCEP) (2008). The ongoing expansion of nanotechnologies may produce novel nanostructures that cause currently unknown forms of hazard. Developing nanomaterials governance that is both effective and proportional to potential risks is critical to the future success of existing and emerging nanotechnologies.

The aim of this chapter is to identify key challenges in developing more effective and internationally coordinated nanomaterials regulation. It seeks to stimulate the debate on how to promote more convergent regulation, primarily between the European Union (EU) and United States (US), but also at the international level.

The EU and the US are worldwide leaders in the scientific and commercial development of nanotechnologies. Their regulatory responses to potential risks will send an important signal worldwide. In the past, they have cooperated in international efforts to harmonize their respective risk regulation, through the Organisation for Economic Co-operation 
and Development (OECD) and the World Trade Organization (WTO). Where successful, such efforts have promoted high levels of protection from risk while enabling scientists and industries to operate freely in the transatlantic economic space.

In some cases, however, transatlantic coordination and cooperation have proved difficult. Differences in legislative frameworks, regulatory cultures, societal risk perceptions and political dynamics can contribute to a divergence of regulatory responses. This was the case, for example, with high-profile transatlantic disputes over hormone-treated beef and genetically modified food, which have had a negative impact on transatlantic relations and trade (Falkner, 2007). These experiences have shown the importance of identifying technological risks and promoting international cooperation at an early stage in the policy process.

This chapter summarizes key findings and policy recommendations of a project that was carried out in 2008-09 by a consortium of research institutions from both sides of the Atlantic: the London School of Economics and Political Science (LSE) and Chatham House (the Royal Institute of International Affairs) in the UK, and the Environmental Law Institute (ELI) and the Project on Emerging Nanotechnologies (PEN) at the Woodrow Wilson International Center for Scholars in the United States. The project, which was funded by a research grant from the European Commission and involved extensive consultation with experts and stakeholders in nanomaterials regulation, resulted in a comparative analysis of European and American regulatory frameworks in three areas: chemicals, food and cosmetics.

This chapter builds on the main project report, entitled Securing the Promise of Nanotechnologies: Towards Transatlantic Regulatory Cooperation (Breggin et al., 2009). Its key policy-relevant findings can be summarized in the following points:

- Developing nanomaterials governance that is both effective and proportional to potential environmental, health and safety (EHS) risks is critical to the future success of existing and emerging nanotechnologies.

- Persistent scientific uncertainty could limit the effectiveness of existing regulatory frameworks and risk assessment approaches. Ongoing international efforts to create scientific building blocks for risk assessment of nanomaterials need to be stepped up and expanded.

- Governments on both sides of the Atlantic need to provide significantly increased funding for research into EHS risks of nanomaterials; they should also promote greater coordination of research funding at an international level. 
- In the light of existing knowledge gaps about the commercial use of nanomaterials, the EU and US should aim to enhance market transparency by strengthening existing mandatory reporting requirements and, where necessary, creating new ones.

- Given the contested nature of consumer labelling, US and EU authorities should explore the implications of potentially diverging labelling requirements for nanomaterials, particularly in the context of international trade obligations.

- In view of the ongoing and accelerating globalization of nanotechnologies, the EU and the US should complement existing international initiatives (for example by the OECD) with the development of international governance capacity in other areas (for example the United Nations Environment Programme and World Health Organization), not least to ensure that developing countries are more involved in international decision-making.

This chapter thus argues that securing the promise of nanotechnologies will require significant levels of international coordination and cooperation. As global leaders in the development and regulation of nanotechnologies, the EU and the US have an important international role to play. Transatlantic cooperation in this area has the potential to provide a model for enhanced international cooperation and is likely to shape the emergence of future international standards and approaches for dealing with potential nanomaterials risks.

\subsection{THE GROWING MARKET FOR NANOMATERIALS}

It is difficult to predict precisely how nanotechnologies and their commercial applications will develop owing to the diversity of potential commercial pathways and the complexity of the nanotechnology value chain. However, as is discussed by Hodge, Bowman and Maynard in their Introduction, the commercial promise of nanotechnologies is beyond doubt. This is reflected not least in growing nanotechnology patent filings and expanding investment in research by both private companies and national governments (Chen et al., 2008; Mandel, 2010). ${ }^{1}$

Consumers are also beginning to see the first fruits of nanotechnology innovation. An inventory ${ }^{2}$ of consumer products containing nanomaterials or enabled by nanotechnologies, maintained by the Project on Emerging Nanotechnologies (PEN) at the Woodrow Wilson International Center of Scholars, lists over 1000 such products that are currently on the market 
in 24 different countries. The vast majority of these products appear in the cosmetics, clothing, personal care, sporting goods, sunscreens and filtration sectors and are available primarily on the US market, with East Asia and Europe following in second and third place. The materials most frequently mentioned as being contained in products are nanoscale silver, carbon, titanium, silicon, zinc and gold. While the PEN inventory relies on self-identified products and may thus potentially overstate (but also understate) the true degree of commercialization of 'nanoproducts', it is indicative of the wide range of commercial applications of nanotechnologies in consumer products.

Nanosciences and nanotechnologies are driving the development of a broad array of products and industries in various sectors ranging from manufacturing and materials to electronics and IT, and healthcare and life sciences. For instance, between 2004 and 2006 the value of manufactured goods and materials incorporating nanomaterials expanded from \$US13 billion to \$US50 billion, and in 2006, \$US1.5 billion worth of nano-enabled drugs were sold. Current projections for the future growth of commercial applications of nanotechnology range from \$US1 trillion to over \$US3 trillion by 2015. But because nanotechnologies are enabling technologies, such estimates do not always distinguish clearly enough between the more limited value-added of nanotechnologies and the larger face-value of products that 'contain' nanotechnology products. Nonetheless, market research estimates suggest that by 2014 as much as 4 per cent of total manufacturing and materials sector output may incorporate nanotechnologies, and 50 per cent of manufactured output in electronics and IT and 16 per cent of manufactured goods in healthcare and life sciences may be nano-enabled (Lux Research, 2008).

\subsection{REGULATORY CHALLENGES OF NANOMATERIALS}

Governments in leading industrialized countries are currently relying on existing frameworks for EHS regulation to deal with nanotechnology risks, making minor adjustments to specific regulations and their implementation in order to close any potential gaps or eliminate uncertainties. These challenges and governments' responses to them are discussed in more detail by, for example, Widmer and Meili (2010) in relation to industrial chemicals, van Calster and Bowman (2010) in relation to the use of nanomaterials in cosmetic products and Gaspar (2010) in relation to therapeutic products. ${ }^{3}$ 


\section{International handbook on regulating nanotechnologies}

Regulators face a number of challenges in dealing with the potential risks of nanomaterials. These challenges are related to a series of uncertainties, with regard to the development and commercial application of nanomaterials, hazards and exposure pathways, the direction and speed of technological change, and the suitability and effectiveness of existing regulatory frameworks. Understanding these uncertainties and reacting effectively and proportionally is imperative for regulators and policymakers as much as for industry and civil society.

\section{Rapid Technological Change}

While the current regulatory focus is on passive nanomaterials, future developments will include active nanomaterials and are likely to converge with other technologies such as information, bio- and cognitive technologies. These future-generation nanomaterials will develop in ways that are difficult to foresee. Regulators will need to constantly expand their knowledge base covering multiple areas of scientific and engineering inquiry and develop flexible responses to a constantly changing technological environment.

How much funding and time will be required to test the nanomaterials flowing into the marketplace? Neither the OECD nor national regulatory bodies have provided public estimates but a recent study indicated that assessing the risks of 190 nanomaterials now in production would require an investment of \$US249 million (assuming optimistic assumptions about hazards) (Choi et al., 2009). The use of tiered testing strategies could reduce this sum and the current low production volumes of some materials may reduce the need to test at all. But the risk assessment challenge is likely to increase in complexity and cost as more materials enter the market and, importantly, as second- and third-generation nanotechnology products and materials enter commercial production.

\section{Uncertainty of Commercialization Paths}

While the number of existing commercial products using nanomaterials keeps growing, uncertainty exists regarding future commercialization paths. As the range of commercial applications expands, governments will have to address potential risks of nanomaterials in diverse regulatory contexts covering different industries and commercial applications, potentially adding to existing uncertainty about the regulatory coverage of nanomaterials risks. 


\section{Uncertainty Regarding Nanomaterials Risks}

A lack of data on hazards and exposure pathways of certain nanomaterials, combined with uncertainty about the applicability of some existing testing methods, are widely recognized impediments to the effective implementation of regulations (see, for example, Chaudhry et al., 2010). Risk regulation under conditions of uncertainty is, of course, not uncommon in areas such as chemical and food safety. Given the significant knowledge gaps on EHS risks of certain nanomaterials, however, it is too early to establish whether existing regulatory frameworks can and will be effective in the face of potential risks. Governments in various countries are currently engaged in more systematic efforts to promote research into EHS risks and the further development of testing methods, but given rapidly evolving nanotechnology research and commercialization, such efforts pose a continuous challenge.

\section{Uncertainty Regarding the Suitability of Regulatory Frameworks}

Analysts have debated for some years whether current laws provide adequate oversight for certain applications of nanotechnologies or whether new legislative instruments are needed. ${ }^{4}$ US and EU regulatory agencies suggest that the existing regulatory framework, consisting of a range of laws and regulations, is broadly sufficient to deal with potential risks associated with nanomaterials, and that only small adjustments or amendments may be needed to regulations and implementation guidelines, in order to close any potential gaps. This, however, remains a matter of debate (see, for example, Breggin et al., 2009: 28-83). It is important to note that much of this depends on how they are implemented. Adequate guidance for implementation and the provision of the necessary resources for regulatory oversight thus become critical factors in developing effective regulatory responses. Uncertainty regarding the regulatory capacity of existing institutions in this area cannot be ruled out, not least because of the novel nature of nanomaterials risks and the limited experiences that regulatory agencies have been able to develop in this area.

\section{Uncertainty Regarding Regulatory and Scientific Resources}

One area that is a recurring theme in debates on regulatory capacity is the question of resources for the implementation of risk regulation frameworks. The challenges that novel technologies such as nanotechnology present require significant investment in human resources. Statutes are a necessary but insufficient condition for success if the regulators lack 


\section{International handbook on regulating nanotechnologies}

enforcement capacity, scientific expertise and foresight. It is too early to say whether regulatory institutions on both sides of the Atlantic have sufficient scientific capacity to deal with the manifold challenges of regulating nanomaterials. What is clear, however, is that the public sector will increasingly have to compete with industry for talent in these emerging technology areas. The search for talent, particularly in the scientific area, thus needs to become a strategic priority, just as it is already in industry.

\subsection{TOWARDS REGULATORY EFFECTIVENESS AND CONVERGENCE: POLICY RECOMMENDATIONS FOR TRANSATLANTIC AND INTERNATIONAL COOPERATION}

What should be done to promote more effective and internationally convergent regulation of nanomaterials? Based on the comparative analysis in our main project report and consultations with relevant experts and stakeholders, we identify four clusters of issues that need to be addressed as part of future efforts to strengthen nanomaterials oversight:

- the creation of the scientific building blocks that are necessary for risk assessment

- the closure of existing knowledge gaps with regard to the commercialization of nanomaterials and potential EHS risks

- questions of societal and ethical perspectives and how they are addressed in risk management, especially through labelling, and

- the strengthening of global governance capacity for nanomaterials oversight.

Before we develop our policy recommendations in greater detail, we need to briefly explain the use of the notion of regulatory convergence in the context of this chapter. We understand convergence to be a process rather than a specific outcome. It involves the gradual adjustment of regulatory frameworks, institutions and practices, but can occur through a variety of processes and mechanisms. These range from informal policy diffusion to international coordination and cooperation, whether formal or informal, and to treaty-based international harmonization efforts. When speaking of the promotion of greater regulatory convergence in the field of nanotechnologies, we therefore have in mind the full range of convergence processes that can be observed in other international policy areas, from environmental to financial regulation, and from trade policy to investment rules. 
While we have focused on ways to promote regulatory convergence, we recognize its limits, in terms of both feasibility and desirability. In the area of EHS regulation, full harmonization of national rules and practices is rarely, if ever, achieved. As discussed in our main report, there are some distinctive benefits, but also costs, that result from regulatory convergence, and policy-makers ultimately need to decide how to balance these. The subsequent discussion reflects this reality and seeks to enlighten the political and regulatory debate by identifying opportunities for, but also barriers to, a movement towards greater consistency and convergence at the transatlantic and international level.

\section{Creation of Scientific Building Blocks}

Recent analyses and scientific reviews have revealed a number of areas in which scientific uncertainty is limiting the effectiveness of existing regulatory frameworks and risk assessment approaches. Fundamental uncertainties exist, for example, with regard to the classification of nanomaterials, the precise definition of nanotechnology and nanomaterials, identification of hazards, exposure levels, and environmental and health effects, in particular over the life-cycle of different nanomaterials (International Council on Nanotechnology, 2008; Scientific Committee on Consumer Products, 2007). In their reviews of regulatory frameworks for nanomaterials, both EU and US agencies have acknowledged that, while nanomaterials are broadly covered by existing frameworks, scientific uncertainties remain to be resolved in order to strengthen the implementation of regulatory oversight mechanisms (European Commission, 2008; EPA, 2007; FDA, 2007).

Broad agreement exists, therefore, on the need to establish a firm scientific basis for risk assessment. In order for regulation to work, regulators need data and scientific tools to develop a clear understanding of the nature of the materials that may cause harm, how to identify these materials, define the different types of risks involved, and establish appropriate testing methods and appropriate and effective methods of measuring nanomaterials in the environment, among others. In a rapidly changing field such as that of the nanosciences, where even the boundaries of what is considered to be a nanoscale material or structure are as yet ill-defined, it is of vital importance to establish those basic scientific tools as the basis for risk assessment and subsequent risk management.

To date, however, many of the scientific building blocks, with regard to definition and characterization of nanomaterials, metrology and testing methods, are as yet missing or have not been internationally standardized. Regulators and experts in the US, Europe and elsewhere are currently 
seeking to fill existing gaps in this area by working together in various international forums, such as the OECD and the International Organization for Standardization (ISO). Our research suggests that ongoing work on creating scientific building blocks for risk assessment needs to be stepped up and expanded if it is to produce results in a timely fashion. The rapid pace of commercialization of nanomaterials demands a greater sense of urgency in this area.

Ongoing bilateral links between relevant regulatory authorities, mainly from the EU and the US, play an important role in this respect. They provide regular opportunities for information exchange and informal learning, and they create a space for regulators to learn from one another's experiences away from the political spotlight. Informal links of this kind are thus an integral element of an international regulatory convergence agenda, but cannot replace more formal, transparent and inclusive processes that are open to a broader range of countries and stakeholders.

Furthermore, a number of standard-setting bodies have focused on the question of scientific and technical terminology in the field of nanotechnologies. They include international bodies such as the ISO and ASTM International, among others. They enjoy a high degree of legitimacy among regulators and industry groups, and are set to make a valuable contribution to the development of congruent and convergent regulatory approaches. Their work is limited in its scope, however, being focused exclusively on standardization in technical and scientific fields, and some civil society groups have voiced concerns about a lack of transparency and participation in the ISO standardization process.

The OECD, in contrast, plays a much wider role in promoting congruent approaches and, to some extent, international convergence in the field of nanomaterials regulation. Having set up two nanotechnology working groups in 2006 (Working Party on Manufactured Nanomaterials - WPMN) and 2007 (Working Party on Nanotechnology - WPN), it is currently the predominant international forum for coordination efforts by regulators and industry experts from the US, the EU and a select group of other countries. It enjoys broad legitimacy in promoting coordination on the building blocks for risk assessment, and is a central institution in the context of transatlantic regulatory convergence. At the same time, more political energy and resources need to be invested in the OECD process, and greater transparency and inclusiveness should be achieved in its work. While it is desirable for the nanotechnology working parties' inclusiveness and transparency to be enhanced in order to facilitate broader participation and openness, the existing structure of the OECD mitigates against a move towards greater transparency and participation. As an organization that represents a select group of industrialized countries, is based on 
inter-governmental decision-making processes and has a limited remit in the development of policy guidance and international coordination, the OECD is unlikely to become the facilitator of a global dialogue on nanotechnology regulation or the host of a global governance framework for nanotechnology.

\section{Closing Knowledge Gaps}

Regulators face two important knowledge gaps, on potential EHS risks associated with the production and use of nanomaterials and on the presence of nanomaterials in commercial products.

A number of authoritative scientific reviews carried out in recent years have revealed significant gaps in our understanding of how nanomaterials interact with the environment and affect the human body. As the RS-RAE reported in their 2004 study, many important questions remain unanswered with regard to the specific properties of nanomaterials, their toxicity and environmental behaviour, and levels of exposure throughout the life-cycle of nanomaterials. A more recent review by the UK's RCEP emphasized the continued knowledge gaps in this area. Its 2008 assessment concluded that 'there is a plausible basis for concern that some manufactured nanomaterials could present a hazard to human health and environment', and that '[h]owever good the research effort, significant uncertainties and areas of ignorance will remain' (RCEP, 2008: 55). Thus, although there is no evidence of actual harm from current applications of nanomaterials, uncertainty about the behaviour of nanomaterials in the environment or in living organisms makes it difficult to know whether there are adverse effects and, if there are, the nature of such effects.

A further complication arises from the rapid and often unpredictable development and commercialization of nanotechnologies in a global context. Technological innovation is proceeding at a pace that governments are finding difficult to keep up with, and, while much of the current regulatory focus is on manufactured nanomaterials, few, if any, efforts are being directed at dealing with the regulation of emerging risks resulting from future-generation nanotechnologies (see, for example, Davies, 2009, 2010; Rodemeyer, 2009). But even gaining a sound knowledge base about the commercial use of first-generation nanotechnologies poses a challenge to regulators today. Uncertainty exists on the extent to which nanomaterials are being manufactured and used by companies as well as traded internationally, making it difficult for regulators to establish unequivocally that all current applications of the new technology are adequately covered by regulations.

These two dimensions of uncertainty are closely linked and complicate 
the search for effective regulatory approaches. Knowing as soon as possible what types of nano-enabled products are on the market, what types of nanomaterials are used and how they move through possible product lifecycles provides some grounding for establishing research needs in the field of EHS risks. Uncertainty in both these areas afflicts regulatory systems around the world. International cooperation on reducing uncertainty with respect to the commercial use of nanomaterials and on EHS risks would help governments in addressing certain regulatory challenges.

\section{EHS risk research}

Accordingly, as a matter of priority, governments need to provide significantly increased funding for research into EHS risks of nanomaterials. They should also promote greater coordination of research funding at a transatlantic and global level. International research coordination has its limits and can be difficult to achieve, but the benefits of improved international coordination of EHS research outweigh the costs. Against the background of strained public finances and urgent research needs, enhanced global cooperation would give a greater sense of strategic direction to existing research efforts and strengthen the basis for sustained research funding streams into the future.

Regulators would also benefit from better access to information available to their counterparts abroad, particularly in the area of potential EHS risks. The sharing of commercially sensitive data poses a problem, however, given regulatory approaches to the protection of confidential business information. We encourage regulators and policy-makers to explore all options available to them, whether through domestic reform or international agreement, to promote better sharing of information on EHS risk-related data for nanomaterials while ensuring commercially sensitive data remain protected.

\section{Reporting of nanomaterials in commercial use}

A second knowledge gap concerns the state of the commercialization of nanomaterials. As mentioned above, uncertainty exists not only about EHS risks of nanomaterials but also with regard to the commercial use of nanomaterials and, specifically, the type of nanomaterials contained in intermediate or consumer products. Many companies themselves are uncertain about the use of such materials within their own industry, and regulators on both sides of the Atlantic have acknowledged that they currently do not have comprehensive knowledge about their presence in commercially traded goods. Recently introduced voluntary substances reporting programmes (for example in the US and UK) are unlikely to close such knowledge gaps. 
Existing attempts to establish comprehensive market registers, such as PEN's product inventory, are laudable but need to be taken further. Given the persistence of these knowledge gaps, governments on both sides of the Atlantic should strengthen existing mandatory reporting requirements and, where necessary, create new ones, with a view to gaining a comprehensive overview of the commercial use of nanomaterials. Given the high degree of interdependence in the global economy, any effort to enhance market transparency through improved reporting schemes would benefit from a coordinated effort at the international level.

Were such a market register to be developed, a number of design questions would have to be addressed, including whether the register is product- or application-based, and whether the register would be available only to regulators or to the public at large. Such an initiative could build on existing initiatives sponsored by non-governmental organizations, such as PEN, to establish market surveys of existing or emerging nanotechnological applications. Whatever design were to be chosen, we believe that this is an area in which international cooperation could provide a fruitful approach towards laying the foundations for more congruent regulatory responses to the challenges of nanomaterials.

\section{Risk Management and Consumer Labelling}

Efforts to promote international coordination and cooperation are currently focused on establishing the scientific building blocks needed for risk assessment. In comparison, moves towards greater coordination of risk management are likely to be less productive, may be premature and would face greater obstacles. At the same time, the internationalization of the nanosciences and nanotechnologies will inevitably bring any differences in risk management approaches into sharper focus, in US-EU relations and internationally. As more and more nanomaterials are adopted commercially and enter global supply chains, differences in national or regional risk management approaches may end up complicating the free flow of goods across national boundaries. For this reason, coordination in the area of risk management will need to be given greater prominence on the international agenda in the coming years.

One important but controversial element of risk management is consumer labelling. Whereas the US has expressed scepticism towards legally binding requirements that specifically target nanomaterials (see FDA, 2007), the EU recently introduced such a requirement for cosmetics and the European Parliament has called for an extension of consumer labelling to other areas, most notably the food sector (see Falkner et al., 2009).

Stakeholders in nanomaterials oversight tend to be sharply divided on 
the need to go beyond this state of affairs by creating more comprehensive labelling requirements, and on whether more convergent approaches could and should be developed in this area. Some warn that labelling would be a costly way to inform the public about the presence of materials that will most likely be of little consequence to human health or the environment. Industry representatives, in particular, have questioned the usefulness and legitimacy of a general labelling requirement for all products that contain nanomaterials and have warned that labels might confuse consumers more than inform them.

On the other hand, civil society groups and others suggest that the labelling of nanomaterials in food and cosmetics products will be of particular importance, not least as a means of building consumer trust through enhanced transparency. Some see this becoming increasingly important as more and more nanomaterials enter the market. While most producer companies remain sceptical about a general labelling requirement, some retail firms (for example supermarkets) are likely to view nano-labelling more favourably as a way of assuring consumers that no risks, whether actual or potential, are hidden from them. Labelling thus should be seen as part of a broader attempt to ensure consumers' 'right to know' and 'informed choice'.

The 'informed choice' argument for nanomaterials labelling is seen by proponents as a means of ensuring that consumers are free to express views not only on the safety of nanomaterials but also on ethical dimensions of the use of nanotechnologies, particularly in food and cosmetics. In this perspective, labelling becomes a tool for embedding nanomaterials regulation in a wider social and ethical context without sacrificing the scientific foundations of the core risk assessment process. Opponents, however, have pointed out that any comprehensive labelling of nanomaterials would be misleading, particularly if it failed to notify consumers of specific health or environmental risks or of specific benefits of the nanomaterials. The question that is at the heart of such disagreements is whether ethical concerns that are unrelated to specific concerns about environmental and health risks are legitimate reasons for introducing a labelling regime. This is clearly a policy issue under continuing political contest.

In view of the contentious nature of labelling, in terms of its general necessity and specific form of implementation, it is unlikely that governments will prioritize international efforts to create new, mandatory, labelling requirements or harmonize existing ones at this time. But they should still consider the implications of different labelling requirements, whether already established or newly created, for the proper functioning of international trade.

Furthermore, if governments were to explore the possibility of 
developing common approaches or standards for nanomaterials labelling, such an undertaking should involve a multi-stakeholder forum to engage relevant groups from industry and civil society in order to give full weight to the different commercial and ethical concerns. Current transatlantic dialogues, such as those within the TransAtlantic Consumers Dialogue (TACD) and the TransAtlantic Business Dialogue (TABD), could provide useful forums for taking this debate forward. Such an effort would be less urgent than the creation of common building blocks for risk assessment, but is nevertheless important in its own right.

\section{Strengthening Global Governance Capacity}

Current efforts to promote greater regulatory convergence have been focused on informal processes of communication and policy learning between national regulatory agencies, as well as formal and informal processes of international coordination through international bodies. In the transatlantic context, US and EU authorities dealing with chemicals, food and cosmetics regulation have engaged in regular but informal transatlantic links, in order to promote the exchange of information and experiences with the implementation of existing nanomaterials regulations. Moreover, regulators, scientists, industry representatives and other stakeholders from civil society have established formal coordination processes through the OECD's two working parties on manufactured nanomaterials and nanotechnology policy. Finally, parallel processes of international standardization, such as those conducted under the auspices of the ISO, are aimed at creating technical and scientific standards that are central to effective risk assessment processes.

No efforts have been undertaken as yet to create a formal, treatybased, international framework for nanomaterials regulation, despite theoretical interest in this possibility (see, for example, Abbott et al., 2010). Our research suggests little, if any, interest in pursuing the more ambitious objective of creating an international treaty on nanomaterials regulation. The political energies that would need to be invested in such a project are better spent on strengthening existing forums for international coordination and adjusting domestic regulatory frameworks where needed. Given the globalized nature of nanotechnology developments and commercialization, however, one cannot rule out the possibility that an international framework treaty might be needed in the future, particularly as new players from the developing world are emerging in the global nanotechnology business.

In view of the ongoing and accelerating globalization of nanotechnologies, governments should perceive the global governance challenges 
arising from nanomaterials in broader terms. The OECD serves an important function as a forum for coordination among leading industrialized countries, but its work should be complemented by the development of international governance capacity in other areas, not least to ensure that developing countries are more involved in international decisionmaking. Other international organizations, such as the United Nations Environment Programme (UNEP) and the World Health Organization (WHO), play important roles in their respective areas of global environmental protection and health promotion, but are only just beginning to identify the potential EHS risks of nanomaterials as emerging areas of concern. The current imbalance in the development of international governance capacity should thus be redressed, and developing countries should be better represented in global regulatory cooperation.

\subsection{CONCLUSION}

In order to secure the promise of nanotechnologies, governments need to develop adequate and appropriate regulatory oversight for nanomaterials. A first, and critical, step in this process is the creation of sound and internationally agreed scientific building blocks for risk assessment. Furthermore, given persisting uncertainties regarding potential environmental and health risks and the commercialization of nanomaterials, governments need to close existing knowledge gaps in these areas, by promoting risk-related research and establishing a comprehensive market register. Governments should also begin to work towards greater international cooperation in risk management, even if achieving coordination and convergence in this area is likely to prove more difficult to achieve. They should consider, in particular, the implications of potentially diverging labelling requirements for international trade and explore the possibility of developing common approaches or standards for labelling.

The EU and US are global leaders in nanosciences and nanotechnologies. They have also taken a lead in developing regulatory approaches for dealing with potential nanomaterials risks. Their decisions on coordination in risk assessment and risk management, within the OECD, ISO and other international coordination forums, will thus send important signals worldwide. But the EU and US should extend their leadership to other areas and institutions of international governance. This would ensure that the twin goals of securing the future of nanotechnologies while safeguarding against potential environmental and health risks of nanomaterials are firmly established at the international level. It would also pave the way for 
a better and more comprehensive representation of emerging economies and developing countries in international decision-making.

\section{NOTES}

1. On US research funding through the National Nanotechnology Initiative, see President's Council of Advisors on Science and Technology (2008). On EU research funding through the Seventh Framework Programme (FP7), see http://cordis.europa.eu/fp7/cooperation/ nanotechnology_en.html

2. Available at http://www.nanotechproject.org/inventories/consumer/.

3. EU and US regulatory authorities have concluded that the existing regulatory framework, consisting of a range of laws and regulations, is broadly sufficient to deal with potential risks associated with nanomaterials, and that only small adjustments or amendments to regulations and implementation guidelines may be needed in order to close any potential gaps. See FDA (2007) and European Commission (2008).

4. See, for example, the American Bar Association's Section Nanotechnology Project, which has produced a series of studies of different regulatory contexts (available at http:// www.abanet.org/environ/nanotech/).

\section{REFERENCES}

Abbott, K.W., D.J. Sylvester and G.E. Marchant (2010), 'Transnational regulation: reality or romanticism?', in Graeme A. Hodge, Diana M. Bowman and Andrew D. Maynard (eds), International Handbook on Regulating Nanotechnologies, Cheltenham, UK and Northampton, MA, USA: Edward Elgar, pp. 525-44.

Breggin, L., R. Falkner, N. Jaspers, J. Pendergrass and R. Porter (2009), Securing the Promise of Nanotechnologies: Towards Transatlantic Regulatory Cooperation. Report, London: Chatham House, accessed at www.chathamhouse.org.uk/nanotechnology

Chaudhry, Q., H. Bouwmeester and Rolf F. Hertel (2010), 'The current risk assessment paradigm in relation to the regulation of nanotechnologies', in Graeme A. Hodge, Diana M. Bowman and Andrew D. Maynard (eds), International Handbook on Regulating Nanotechnologies, Cheltenham, UK and Northampton, MA, USA: Edward Elgar, pp. $124-43$.

Chen, H., M.C. Roco, X. Li and Y. Lin (2008), 'Trends in nanotechnology patents', Nature Nanotechnology, 3, 123-5.

Choi, J., G. Ramachandran and M. Kandlikar (2009), 'The impact of toxicity testing costs on nanomaterial regulation', Environmental Science and Technology, 43(9), 3030-34.

Davies, J.C. (2009), Oversight of Next Generation Nanotechnology, Washington, DC: Project on Emerging Nanotechnologies.

Davies, J.C. (2010), 'From novel materials to next generation nanotechnology: a new approach to regulating the products of nanotechnology', in Graeme A. Hodge, Diana M. Bowman and Andrew D. Maynard (eds), International Handbook on Regulating Nanotechnologies, Cheltenham, UK and Northampton, MA, USA: Edward Elgar, pp. 545-70.

Environmental Protection Agency (EPA) (2007), Nanotechnology White Paper, Washington, DC: EPA.

European Commission (2008), Communication from the Commission to the European Parliament, the Council and the European Economic and Social Committee: Regulatory Aspects of Nanomaterials, Brussels: EC. 


\section{International handbook on regulating nanotechnologies}

Falkner, R. (ed.) (2007), The International Politics of Genetically Modified Food: Diplomacy, Trade and Law, Basingstoke: Palgrave Macmillan.

Falkner, R., L. Breggin, N. Jaspers, J. Pendergrass and R. Porter (2009), Consumer Labelling of Nanomaterials in the EU and US: Convergence or Divergence?, EERG briefing paper 2009/03, London: Chatham House.

Food and Drug Administration (FOA) (2007), Nanotechnology: A Report of the US Food and Drug Administration Nanotechnology Task Force, Washington, DC: FDA.

Gaspar, R. (2010), 'Therapeutic products: regulating drugs and medical devices', Graeme A. Hodge, Diana M. Bowman and Andrew D. Maynard (eds), International Handbook on Regulating Nanotechnologies, Cheltenham, UK and Northampton, MA, USA: Edward Elgar, pp. 291-320.

Hodge, G.A., D.M. Bowman and A.D. Maynard (2010), 'Introduction: the regulatory challenges for nanotechnologies', in Graeme A. Hodge, Diana M. Bowman and Andrew D. Maynard (eds), International Handbook on Regulating Nanotechnologies, Cheltenham, UK and Northampton, MA, USA: Edward Elgar, pp. 3-24.

International Council on Nanotechnology (2008), Towards Predicting Nano-Biointeractions: An International Assessment of Nanotechnology Environment, Health and Safety Research Needs, Geneva: IRGC.

Lux Research (2008), Overhyped Technology Starts to Reach Potential, New York: Lux Research, accessed 15 September 2009 at http://www.luxresearchinc.com/press/ RELEASE_Nano-SMR_7_22_08.pdf.

Mandel, G.N. (2010), 'Regulating nanotechnology through intellectual property rights', in Graeme A. Hodge, Diana M. Bowman and Andrew D. Maynard (eds), International Handbook on Regulating Nanotechnologies, Cheltenham, UK and Northampton, MA, USA: Edward Elgar, pp. 388-405.

President's Council of Advisors on Science and Technology (2008), The National Nanotechnology Initiative: Second Assessment and Recommendations of the National Nanotechnology Advisory Panel, Washington, DC: PCAST.

Rodemeyer, M. (2009), New Life, Old Bottles: Regulating First-Generation Products of Synthetic Biology, Washington, DC: Synthetic Biology Project.

Royal Commission on Environmental Pollution (2008), Novel Materials in the Environment: The Case of Nanotechnology, London: RCEP.

Royal Society and the Royal Academy of Engineering (RS-RAE) (2004), Nanoscience and Nanotechnologies: Opportunities and Uncertainties, London: RS-RAE.

Scientific Committee on Consumer Products (2007), Opinion on Safety of Nanomaterials in Cosmetic Products, Brussels: EC.

van Calster, G. and D.M. Bowman (2010), 'A good foundation? Regulatory oversight of nanotechnologies using cosmetics as a case-study', in Graeme A. Hodge, Diana M. Bowman and Andrew D. Maynard (eds), International Handbook on Regulating Nanotechnologies, Cheltenham, UK and Northampton, MA, USA: Edward Elgar, pp. 268-90.

Widmer, M. and C. Meili (2010), 'Approaching the nanoregulation problem in chemicals legislation in the EU and US', in Graeme A. Hodge, Diana M. Bowman and Andrew D. Maynard (eds), International Handbook on Regulating Nanotechnologies, Cheltenham, UK and Northampton, MA, USA: Edward Elgar, pp. 238-67. 